Supporting Information

\title{
A self-charging supercapacitor for a patch-type glucose sensor
}

\author{
Hye-Jun Kil, Seung-Rok Kim, and Jin-Woo Park*
}

Department of Materials Science and Engineering, Yonsei University, Seoul, 03722, Korea

*Corresponding author's E-mail: jwpark09@yonsei.ac.kr 


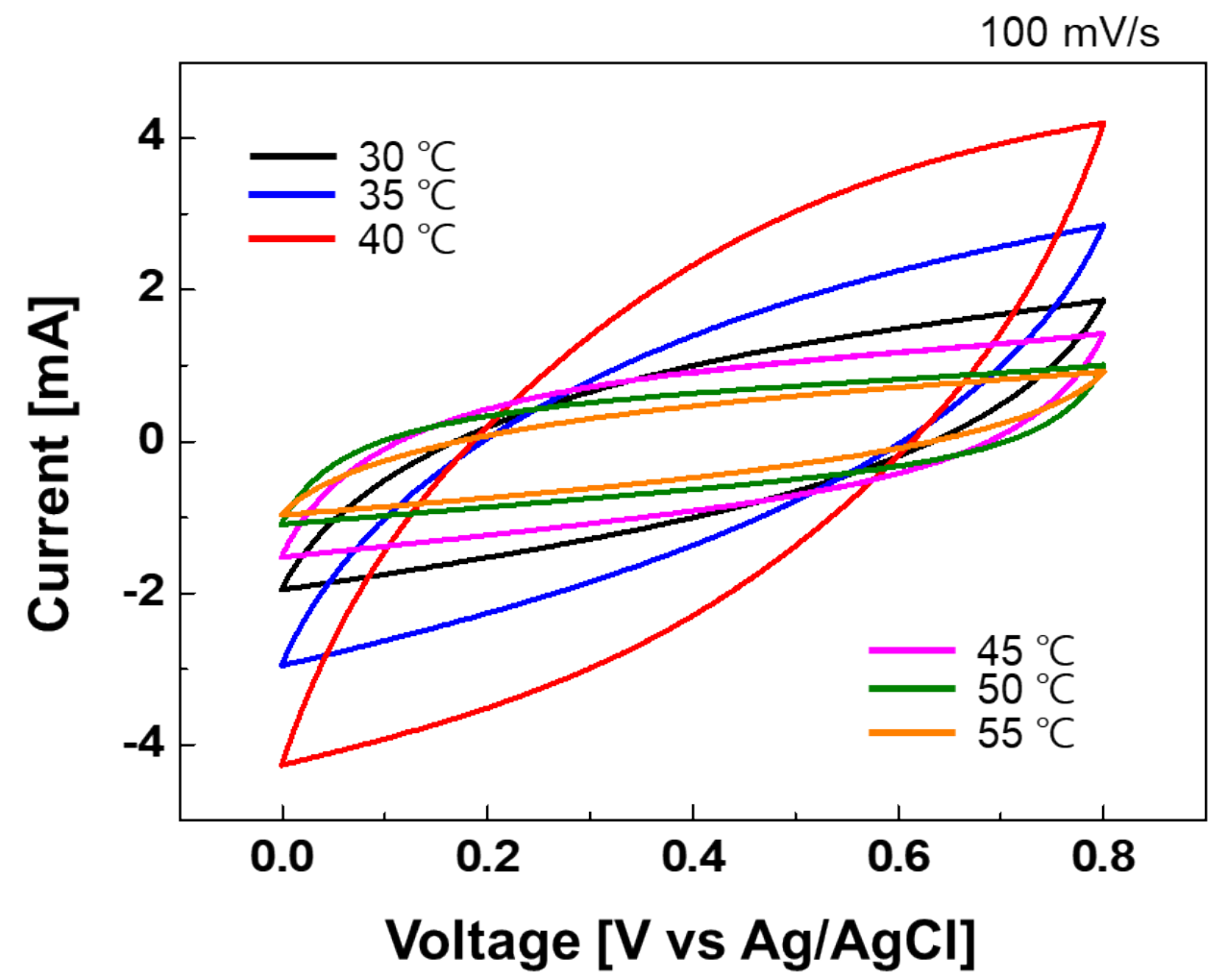

Figure S1. CV curve of the enzyme-coated microneedle when the temperature of the skin and the $5 \mathrm{mM}$ glucose solution was in the range of 30 to $55^{\circ} \mathrm{C}$ to show the difference in the reaction of enzymes by temperature. 


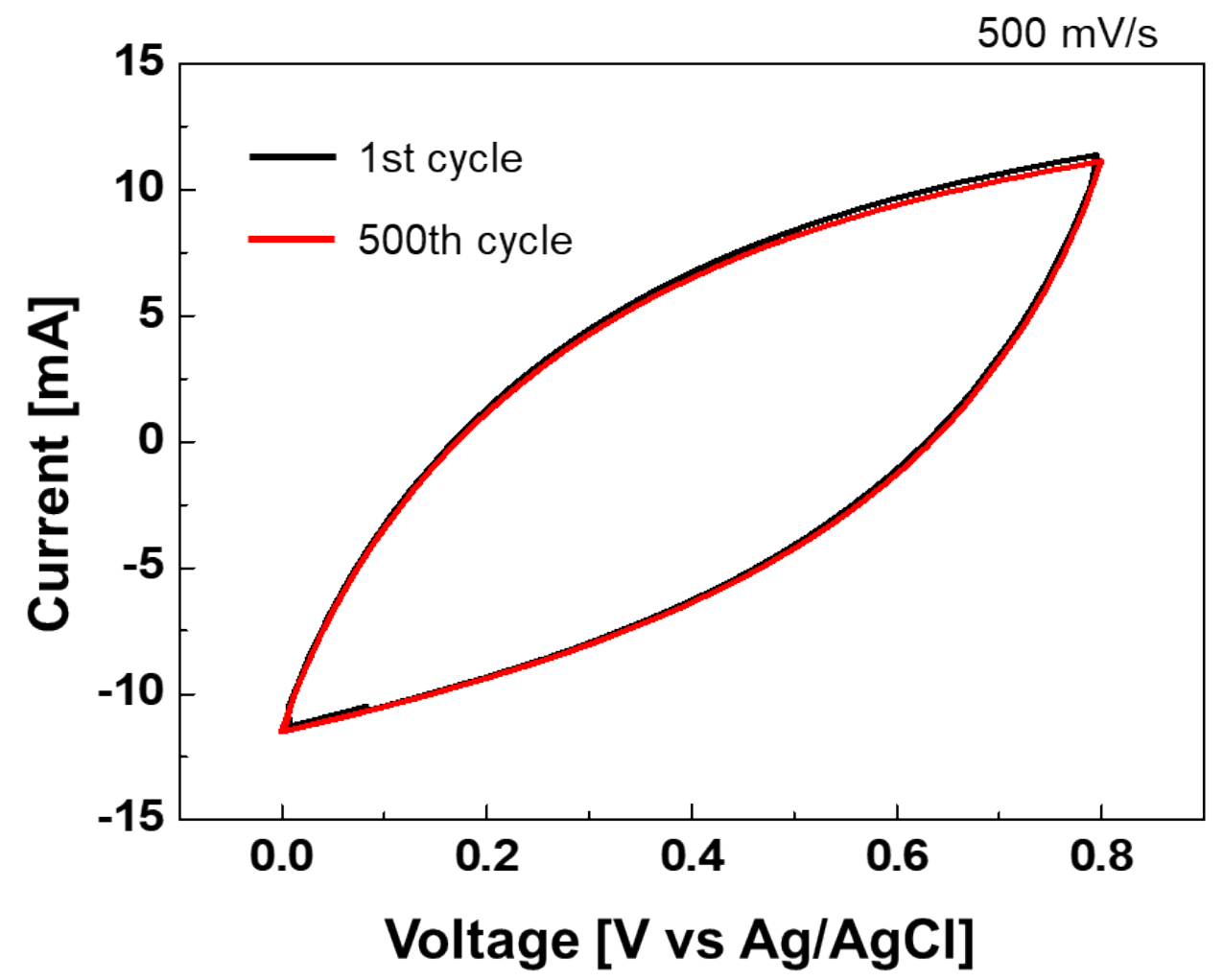

Figure S2. Comparison of the first and 500th CV curves to confirm the stability of the enzymecoated microneedle. 


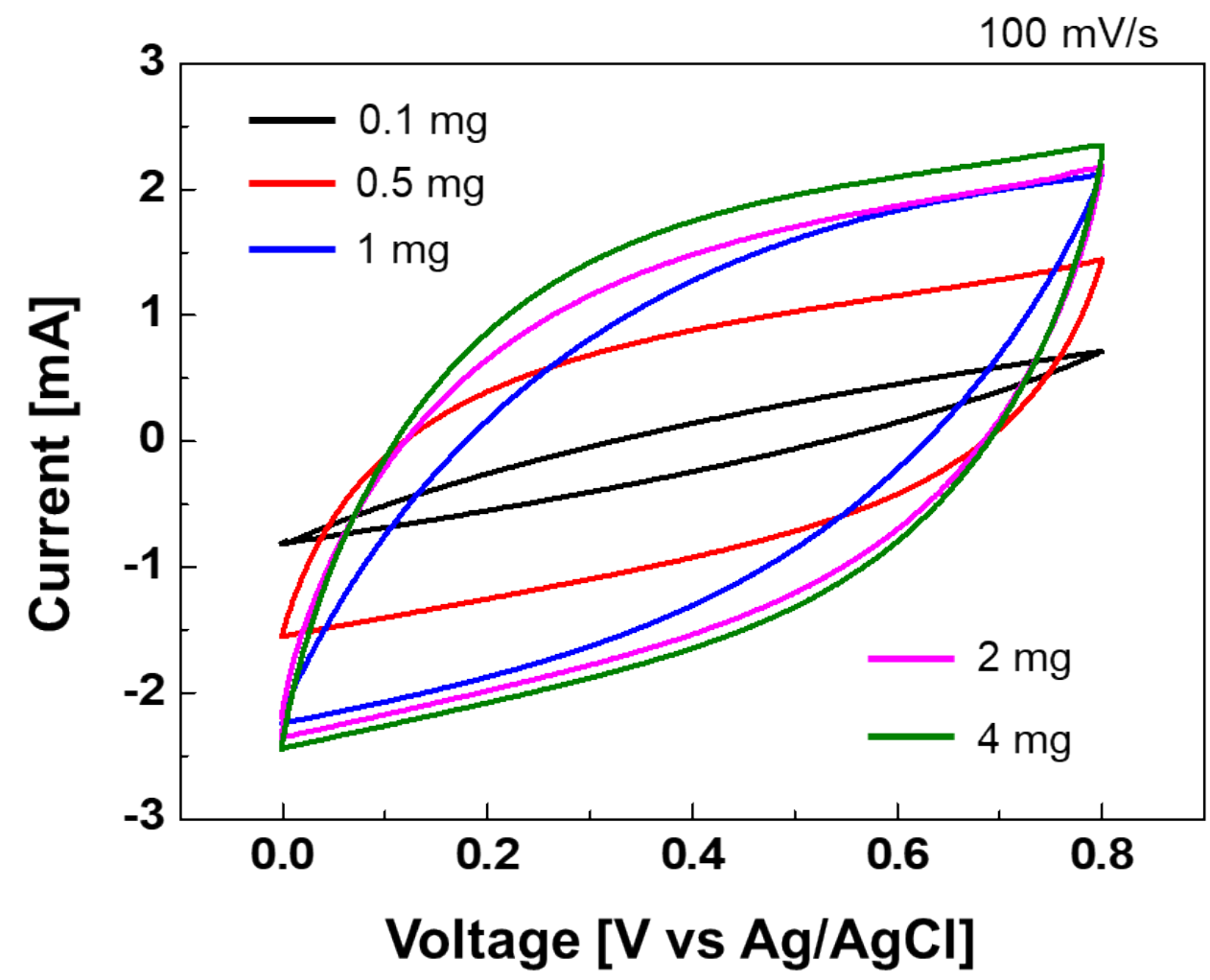

Figure S3. Comparison of each CV curve reacting in a $5 \mathrm{mM}$ glucose solution when the coating amount of the enzyme GOx was $0.1,0.5,1,2$, and $4 \mathrm{mg}$. When the amount of enzyme used for coating was $1 \mathrm{mg}$ or more, it was observed that the CV area was similar. 

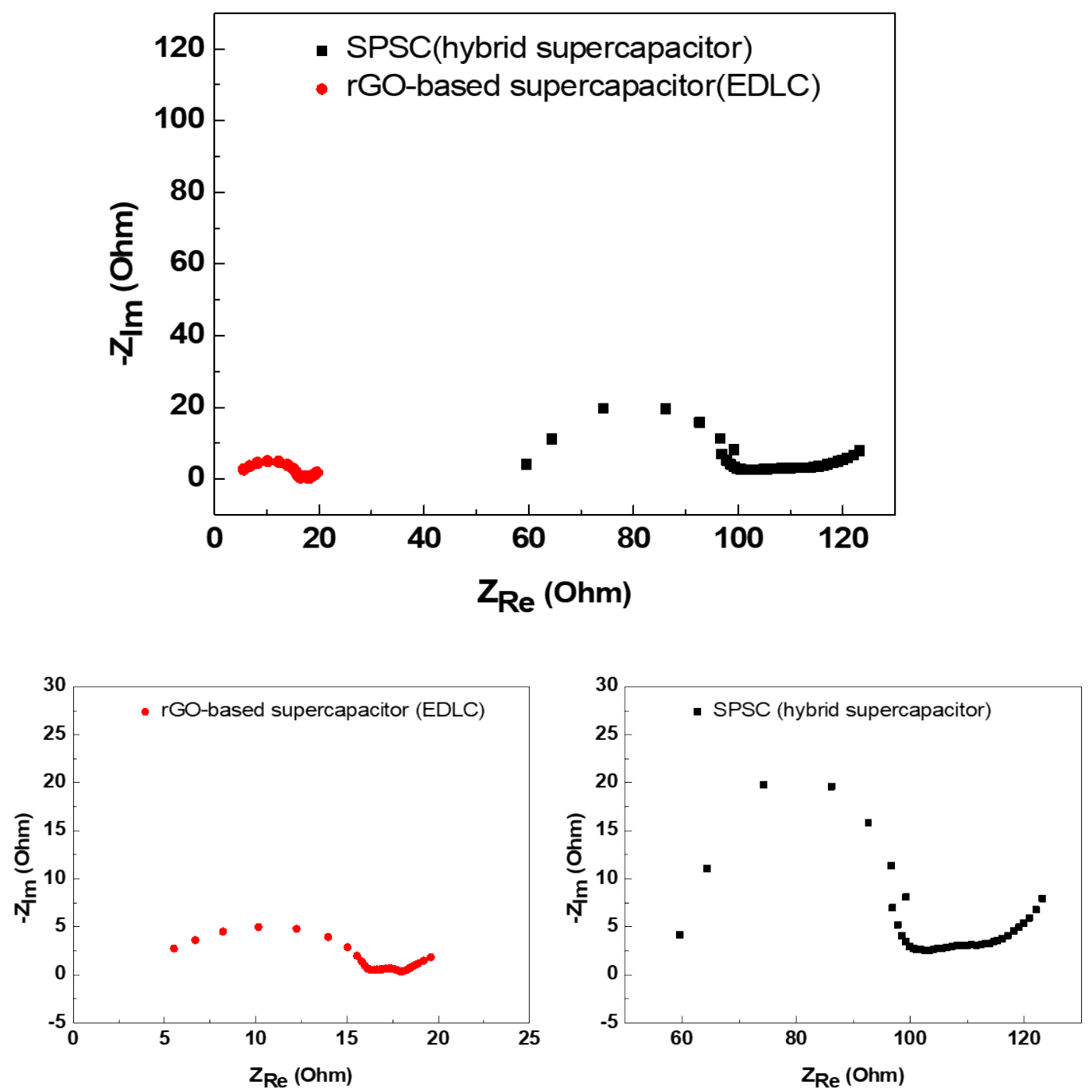

Figure S4. Impedance results measured by SP-300 potentiostat (Biologic) to compare the conductivity of supercapacitors. The supercapacitor whose electrodes are composed of only rGO is an electric double layer capacitor (EDLC). In the case of the SPSC, which forms all-inone structure with the glucose sensor, it is a hybrid supercapacitor with different components of both electrodes because it meets PEDOT:PSS used as an electrode of the glucose sensor. It was confirmed that the resistance of the SPSC was higher than that of EDLC. 